Итак, в результате проведенного исследования установлена принципиальная возможность применения распределения Вейбулла-Гудрича к выравниванию скоростей ветра на уровне ветроизмерительного прибора. Это открывает новые возможности для обработки информации о ветровом режиме с применением средств вычислительной техники для решения широкого круга научных и практических задач. К ним можно отнести оценку ветрового напора на здания и сооружения, застойных состояний атмосферы, потенциальных и утилизируемых ветроэнергетических ресурсов и их распределения по территории. Для оценки параметров этого распределения рекомендуется использовать методы моментов и наименьших квадратов, минимизирующих объем вычислительных работ. Параметры распределения, оцененные с использование этих параметров, позволяют надежно определять средние скорости ветра и характеристики изменчивости.

\section{Библиографический список}

1. Анапольская Л.Е. Режим скоростей ветра на территории СССР. Л., 1961. 199 с.

2. Брагинская Л.Л., Каган Р.Л. К вопросу об аппроксимации распределения скоростей ветра // Тр. ГГО. 1982. Вып. 447. С. 49-57.

3. Кошинский С.Д. Из опыта расчета некоторых статистических характеристик ветра и параметров функции распределения вида $f(x)=\exp \left[-\left(\frac{v}{\beta}\right)^{\gamma}\right]$ на электронновычислительных машинах // Тр. НР ГМЦ СССР. 1969.

Вып. 2. С. 44-53.

4. Справочник по климату СССР: В 5 ч. Ч. 3, вып. 12-13. Л., 1967.

5. Научно-прикладной справочник по климату СССР. Л., 1988. Сер. 3. Вып. 12-13.

УДК 91(075.8)+929

\title{
САРАТОВСКИЙ МЕЖРЕГИОНАЛЬНЫЙ ЦЕНТР КОСМИЧЕСКОГО МОНИТОРИНГА КАК ФАКТОР ИНТЕГРАЦИИ НАУКИ, ОБРАЗОВАНИЯ И БИЗНЕСА
}

\section{В.3. Макаров, А.Н. Чумаченко}

Саратовский государственный университет, кафедра физической географии и ландшафтной экологии, ${ }^{1}$ кафедра геоморфологии и геоэкологии E-mail: geogr@sgu.ru

В статье рассмотрены результаты деятельности научно-внедренческого образовательного центра геоинформационных технологий (ГИС-центр). Кратко освещены выполненные в ГИС-центре проекты по внедрению ГИС-методологии в научно-производственные и производственные организации Поволжья и намечены основные направления работы новой инновационной структуры СГУ - межрегионального центра космического мониторинга.

Ключевые слова: инновационная деятельность, геоинформатика, ГИС-технологии, комплексный территориальный анализ и региональное планирование, дистанционное зондирование, космические снимки.

Saratov Interregional Centre of Space Monitoring as a Factor of Science, Education and Business Integration

\section{V.Z. Makarov, A.N. Chumachenko}

The article represents results of scientific-innovation educational centre of geoinformational technologies (GIS-centre) activity. Also briefly reports projects realized by GIS-centre concerning of GIS methodology implementation to Povolzhie' scientific-production and production organizations and lay down general working trends of the Saratov State University new innovation organization - the interregional centre of space monitoring.

Key words: innovation activity, geoinformatic, GIS-technology, complex territorial analysis and regional planning, remote sensing, space images, spacephotomaps.

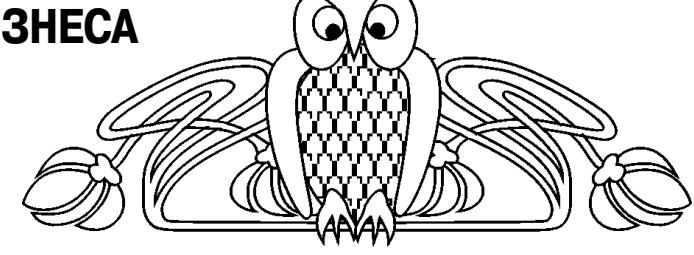

\section{Введение}

Альтернативы инновационному развитию страны на сегодняшний день нет. Этот широко используемый тезис не оспаривается. В то же время призывы к инновационному развитию так и останутся призывами, если среди прочего не заработают инновационные университетские центры. Нет в нашей стране других структур, в которых могли бы быть реализованы задачи не только генерирования новых идей, разработки прорывных технологий, но, одновременно, и задачи подготовки высококлассных специалистов, способных подхватить эти идеи, внедрить новые технологии в нашу жизнь. Как показывает опыт, отсутствие хотя бы одной из составляющих инновационного развития не просто тормозит процесс развития, a, по сути, останавливает его. Разумеется, указанные условия являются необходимыми, но далеко не достаточными для поступательного движения. В частности, нужно, чтобы университетские научнообразовательные центры выступали фокусом интеграции приоритетных научных направлений, современных образовательных парадигм и запросов бизнеса.

В Саратовском государственном университете создан и более 3 лет работает научно- 
внедренческий образовательный центр геоинформационных технологий (ГИС-центр).

Цель данной статьи - сделать обзор выполненных в ГИС-центре работ и рассмотреть наиболее актуальные задачи, стоящие перед новой, недавно созданной структурой - межрегиональным центром космического мониторинга. Это новое направление в инновационной деятельности Саратовского национального исследовательского университета.

\section{Развитие геоинформационного направления}

Геоинформационное направление на протяжении последнего десятилетия является стержневым в научно-исследовательской и образовательной деятельности географического факультета университета. Поэтому появление в его составе ГИС-центра неслучайно.

За последние два десятилетия в лабораториях урбоэкологии и регионального анализа, геоинформатики и тематического картографирования, которые и стали основой ГИС-центра, было выполнено большое количество разнообразных проектов. Заказчиками и полноценными партнерами многих работ являлись различные бизнес-структуры, государственные организации Саратовской области и других регионов страны. Среди них: ОАО «ВНИПИГАЗДОБЫЧА», ОАО «Саратовнефтегаз», ГУПП «Институт Саратовгражданпроект», Комитет по охране окружающей среды и природных ресурсов Саратовской области, ОАО «РосЖелДорПроект», НПО «Элита Поволжья», городской центр санэпиднадзора, Саратовская гидрогеологическая экспедиция, ПЧИ «Микроб», Саратовский филиал ОАО ГипродорНИИ, Московский государственный университет им. М.В. Ломоносова, Саратовский государственный медицинский университет, спецкомбинат «Радон» и многие другие.

Перечень научных, научно-производственных и производственных структур нашего региона, для которых задача использования геоинформационных технологий стоит на повестке дня, обширен. И он, несомненно, будет увеличиваться. В решении этой задачи уже сейчас велика роль университетского ГИС-центра, и она, очевидно, будет возрастать в силу нескольких важных причин, среди которых отметим следующие:

1. Научно-внедренческий образовательный центр геоинформационных технологий включает в себя весь спектр необходимых условий для реализации геоинформационных проектов в нашем регионе на самом высоком уровне. Высококвалифицированные специалисты центра являются разработчиками методологических и методических подходов в создании и использовании ГИС. В ГИС-центре разработаны:

- принципиальные основы методологии детального анализа и учета всего многообразия специфики территориальных различий городских и сельских местностей, не имеющие мировых аналогов [1-3];

- концептуальные основы, методология, структура и содержание комплексной многоуровневой и многоцелевой ГИС для решения задач управления регионами, муниципальными образованиями и городами [4];

- методология комплексного геоинформационного территориального анализа геоэкологических, геодемографических и социальноэкономических структур и процессов;

- алгоритмы решения различных регионально-планировочных, градостроительных и природоохранных задач на основе специализированных блоков ГИС $[5,6]$;

2. В ГИС-центре накоплен уникальный научно-практический опыт в области комплексного территориального анализа, созданы и внедрены в практику работы различных организаций многочисленные тематические электронные атласы и действующие отраслевые геоинформационные системы $[6,7]$. При этом исследования центра и внедренные разработки охватывают Саратовскую область в целом, муниципальные районы области, отдельные территории региона, имеющие важное социально-экономическое, рекреационное, природоохранное значение, а также территории городов Саратовской области [8].

В ГИС-центре имеются все возможности для создания отраслевых и комплексных географических информационных систем, которые отвечали бы разнообразным потребностям государственных и муниципальных служб, позволяли на практике принимать обоснованные решения по управлению территорией.

3. Одной из серьезнейших проблем на сегодняшний день в сфере внедрения геоинформационных технологий является нехватка квалифицированных пользователей конечных ГИС-продуктов на местах и малочисленность специалистовгеоинформатиков, способных поддерживать и развивать ГИС. Научно-внедренческий образовательный центр геоинформационных технологий обеспечивает подготовку и переподготовку специалистов в области геоинформатики. Саратовский университет - один из немногих вузов страны, в котором ведется обучение студентов по специальности 351400 «Прикладная информатика в географии». Созданы все условия для подготовки высококлассных специалистов. С целью подготовки кадров высшей квалификации открыта аспирантура по специальности «Геоинформатика». Создана система переподготовки сотрудников различных административных и коммерческих структур для работы с блоками ГИС: открыт центр обучения и переподготовки кадров. Выпускники центра получают свидетельство о повышении квалификации государственного образца. Разработаны концепция создания на базе ГИС Саратовской области учебно-методических 
материалов для высших и средних учебных заведений нашей области, структура и содержание мультимедийного географического атласа для школы.

4. Программное и техническое оснащение ГИС-центра находится на уровне лучших мировых стандартов, что является уникальным не только для нашего региона, но и для страны в целом. Для геодезических работ, составляющих основу геоинформационных проектов, закуплены высокоточные нивелиры, электронные теодолиты и тахеометры, светодальномеры, GPS, программное обеспечение для обработки геодезических данных. Приобретен мобильный геодезический комплекс, оснащенный самым современным высокоточным оборудованием спутниковой навигации. Создан кабинет фотограмметрии, оснащенный мощнейшими графическими станциями и специализированными стереомониторами, предназначенными для стереофотограмметрической обработки аэро- и космических данных. В рамках инновационного проекта закуплены оборудование для кабинета математико-картографического моделирования, специализированные системы ввода и вывода картографической продукции, приборы для обработки данных полевых исследований и многое другое.

Центр оснащен полным набором разнообразных лицензионных программных продуктов, необходимых для решения задач ввода и вывода графической информации, создания атрибутивных баз данных, фотограмметрической обработки данных дистанционного зондирования и их автоматизированного дешифрирования, построения различных математико-картографических моделей состояния окружающей территории и др.

\section{Создание центра по обработке данных космической съемки}

В настоящее время НВОЦ «ГИС-центр» свои усилия сосредоточил на выполнении про- екта «Разработка и внедрение методологии комплексного территориального анализа на основе ГИС-технологий и данных дистанционного зондирования в работу различных ведомств и организаций Саратовской области и Нижнего Поволжья». Основная задача проекта состоит во внедрении в разные сферы народного хозяйства и процесс образования современных теоретикометодических и практических достижений геоинформатики, геоэкологии и регионального планирования.

Проект выполняется в соответствии с двумя приоритетными направлениями развития науки, технологий и техники в Российской Федерации:

a) информационно-телекоммуникационные системы;

б) рациональное природопользование.

В рамках этого проекта решается задача создания межрегионального центра космического мониторинга, предназначенного для приема, хранения и обработки данных дистанционного зондирования Земли. Получаемая со спутников информация будет накапливаться, сравниваться и постоянно обновляться. Она послужит базовой информационной основой для разработки и внедрения многоцелевых и специализированных геоинформационных систем, станет основой мониторинга территориальных структур региона.

Центр космического мониторинга способен обеспечить прием и обработку информации $\mathrm{X}$-диапазона, передаваемой с низкоорбитальных природно-ресурсных искусственных спутников Земли в диапазоне 8 ГГц со скоростью до 170 Мбит/с в одном канале. Прием осуществляется с искуственных спутников Земли (ИСЗ) Terra, Aqua, EROS A, EROS B. Некоторые параметры спутниковых систем и характеристики получаемых данных приведены в табл. 1, 2).

Некоторые характеристики спутниковых систем

\begin{tabular}{|l|c|c|c|c|}
\hline \multicolumn{1}{|c|}{ Спутник } & Тип орбиты & $\begin{array}{c}\text { Высота орбиты, } \\
\text { км }\end{array}$ & $\begin{array}{c}\text { Наклонение, } \\
\text { град. }\end{array}$ & $\begin{array}{c}\text { Период обраще- } \\
\text { ния, мин }\end{array}$ \\
\hline EROS A/EROS B & Солнечно-синхронная, круговая & $510+/-40$ & 97,3 & 94 \\
\hline Terra/Aqua & Солнечно-синхронная, круговая & 705 & 98,2 & 98,8 \\
\hline
\end{tabular}

Характеристика изображений, получаемых со спутников EROS

\begin{tabular}{|c|c|c|c|c|c|}
\hline Спутник & $\begin{array}{c}\text { Прибор / ре- } \\
\text { жим съемки }\end{array}$ & $\begin{array}{c}\text { Спектральный } \\
\text { диапазон }\end{array}$ & $\begin{array}{c}\text { Простран- } \\
\text { ственное раз- } \\
\text { решение, м }\end{array}$ & $\begin{array}{c}\text { Полоса об- } \\
\text { зора, км }\end{array}$ & $\begin{array}{c}\text { Повторяемость съемки } \\
\text { одной территории (для } \\
\text { одного спутника) }\end{array}$ \\
\hline EROS A & PAN & $\begin{array}{c}0,5-0,9 \\
\text { (Зеленый - БИК) }\end{array}$ & 1,9 & 14 & 1 раз в 3-4 сут \\
\hline EROS B & PAN & $\begin{array}{c}0,5-0,9 \\
\text { (Зеленый - БИК) }\end{array}$ & 0,7 & 7 & 1 раз в 3-4 сут \\
\hline
\end{tabular}


Системы управления земной станцией приема спутниковой информации и предварительной обработки данных обеспечивают:

- автоматическую проверку функционирования аппаратной части;

- расчет прохождения ИСЗ через зону видимости и автоматическую активизацию работы земной станции, расчет траектории ИСЗ и управление антенной системой для сопровождения ИСЗ;

- проведение систематической геометрической коррекции растровых данных;

- улучшение изображений, радиометрическую коррекцию (управление контрастом и яркостью изображений, линейное и нелинейное контрастирование и т.п.);

- географическую привязку спутниковой информации;

- тематическую обработку многозональных снимков, нейросетевую классификацию и GTM, объектно-ориентированную классификацию, расчет радиационного баланса, гидрологического моделирования, интерактивное создание тонально-сбалансированных мозаик изображения земной поверхности на снимке, увеличение пространственного разрешения, проведение анализа изменения территории во времени, 3D моделирование и визуализацию и пр.;

- формирование выходных продуктов стандартных уровней обработки в распространенных обменных форматах, проведение предпечатной подготовки и пр.

Нет необходимости отмечать инновационный характер методов космического мониторинга земной поверхности. Задача состоит в быстрейшем и наиболее эффективном их использовании, объединении с ГИС-технологиями.

\section{Обработка и использование данных дистанционного зондирования и анализ архива космоснимков}

Создание межрегионального космического центра мониторинга позволит выдвинуть Саратовский университет в число ведущих отечественных центров дистанционного изучения Земли. Появляется возможность решения практических задач, связанных с мониторингом окружающей среды, исследованием динамики природных процессов и явлений, поддержки принятия решений в реальном времени, оперативного реагирования на проявления рисковых ситуаций, анализом причин и прогнозирования последствий чрезвычайных ситуаций и пр.

На наш взгляд, наиболее перспективно использование данных дистанционного зондирования Земли в следующих отраслях народного хозяйства Саратовской области и сферах управления:

- сельском хозяйстве - мониторинг состояния земель, деградации почв, состояния сельскохозяйственных культур, соотношения различных типов землепользования, состояния пастбищ, прогноз урожаев, наличия и толщины снегового покрова, загрязненности снегового покрова.

- лесном хозяйстве - анализ лесопокрытой площади, гарей, вырубок, деградации древостоев, породного состава, пораженности насекомыми, оценка пожароопасности и мониторинг лесных пожаров.

- водном хозяйстве и управлении МЧС по Саратовской области - оценка паводкоопасности, состояния водотоков и водоемов, эвтрофикации водоемов, инвентаризация прудов и водохранилищ, анализ состояния плотин, абразии берегов, обмеления и заиливания водотоков и водоемов, состояния водоохранных зон.

- городском планировании - изучение плотности и характера застройки, направления роста населенных пунктов, состояния пригородных зон, границ землепользования, локализации свалок, зон загрязнения, утечек из канализационных систем и водопроводной сети и пр.

- комитете природопользования и охраны окружающей среды - может использовать информацию по оценке распространенности и интенсивности водной эрозии, загрязнению водоемов и водотоков, загрязнению и эрозии почв и грунтов, состоянию месторождений минерального сырья, загрязнению снегового покрова, прозрачности атмосферы, состоянию особо охраняемых природных территорий.

Это далеко не полный перечень возможных направлений использования данных спутникового зондирования. Подчеркнем, что кроме наземной станции приема космической информации центр космического мониторинга располагает геоинформационным программноаппаратным комплексом (геопорталом), предназначенным для интерактивной работы с графически привязанной информацией через сеть Интернет/Интранет. Данный геопортал наполнен обширным архивом космических изображений разного территориального охвата. Отметим некоторые из них:

- космические изображения сверхвысокого разрешения программ IKONOS и QuickBird. Пространственное разрешение изображений не более 1 м (панхроматические) и пространственное разрешение не более 4 м (мультиспектральные). Данные снимки получены на территории городов Саратов, Энгельс, Вольск, Балаково;

- космические изображения высокого разрешения (2,0-2,5 м) на отдельные участки Саратовской области, прежде всего пригородные зоны, долина Волги и пр.;

- космические снимки программы IRS c пространственным разрешением не более 5,8 м (панхроматические) и пространственным разрешением не более 23,5 м (мультиспектральные) на всю территорию Саратовской области;

- космические снимки программы Landsat 7 с пространственным разрешением не более 15 м 
(панхроматические) и пространственным разрешением не более 30 м (мультиспектральные) на территорию Российской Федерации.

Необходимо отметить, что все архивные снимки прошли процедуру предварительной обработки с целью создания геопривязанных цветосинтезированных тонально-сбалансированных мозаичных покрытий.

Геопортал не просто содержит определенные материалы, но и дает возможность работать с ними, выполняя слеующие операции:

- работу с растровыми (Tiff/GeoTiff, Erdas Imagine, BMP, Jpeg/Jpeg2000, MrSid, ECW и др.) и векторными (ESRI Shapefile, MapInfo File, GPX, KML и др.) форматами данных;

- интерактивный просмотр комбинации векторных и растровых слоев; масштабирование растровых и векторных слоев;

- предоставление основных и дополнительных географических инструментов (измерение расстояния и площади, определение координат точки);

- загрузка пользователем собственных векторных и растровых файлов для просмотра поверх мозаики спутниковых изображений; сохранение нарисованных объектов (точек, линий, полигонов) в виде shp/tab файлов.

Кроме того, предоставляются:

- поисковые инструменты (поиск по координатам объектов, топонимический поиск), получение информации через Интернет;

- возможность обновления и расширения состава информационного обеспечения ПАК;

- экспорт-импорт данных из программного обеспечения базовой программы ArcGis;

- импорт в качестве входной информации векторных и растровых данных основных распространенных форматов, ее обработка и сохранение в форматах, используемых интерактивной системой предоставления сервисов;

- импорт оперативных метаданных и данных космической съемки в форматах стандартных продуктов, подготавливаемых средствами наземной приемной станции;

- обеспечение подготовки и записи выходных продуктов в виде геопривязанных или геокодированных изображений в формате GeoTIFF; обеспечение подготовки и передачи метаданных и снимков для отображения.

Важно отметить, что обработка данных дистанционного зондирования выполняется в оболочке геоинформационной системы Саратовской области, включающей цифровые карты региона и отдельных, наиболее важных территорий и объектов (городов, промышленных площадок, полигонов и пр.) с соответствующими атрибутивными базами данных.

Особо подчеркнем важную роль спутниковой информации в интеграции с географическими информационными системами (ГИС), где результаты дистанционного зондирования поверхности
Земли из космоса являются регулярно обновляемым источником данных, необходимых для формирования природно-ресурсных карт и атласов, кадастров и других приложений.

\section{Заключение}

1. На географическом факультете Саратовского госуниверситета в структуре инновационных ГИС-центра и Центра космического мониторинга разработана методология комплексного территориального анализа на разных масштабных уровнях - муниципальных образований и региональном. Данная методология успешно апробирована и внедрена в работу многих муниципальных и государственных организаций, акционерных и частных компаний.

2. Создаваемый центр по приему, обработке и анализу спутниковой информации, будет интегрирован с ГИС-центром. Это позволит создать многоцелевую полнофункциональную ГИС-Саратовской области.

Оперативный прием и обработка данных дистанционного зондирования, выполняемые в оболочке геоинформационной системы Саратовской области, позволят решать многие текущие и стратегические задачи, которые стоят перед народным хозяйством области: деградация и загрязнение земель, маловодье, нерациональное землепользование, угроза лесных пожаров и др.

3. Инновационные научно-исследовательские центры географического факультета СГУ располагают необходимыми материальными, кадровыми и интеллектуальными ресурсами, опытом работы по созданию интегрированных ГИС, включающих совместную обработку цифровых карт и цифровых космических снимков. Сотрудники центров готовы оказать содействие в становлении и развитии ГИС-технологий и методов использования Д33 в различных органах управления народным хозяйством Саратовской области, а также в службах оперативного контроля за природными ресурсами и экологической ситуацией в целях принятия оптимальных и своевременных управленческих решений.

\section{Библиографический список}

1. Макаров В.3. Ландшафтно-экологический анализ крупного промышленного города. Саратов: Изд-во Сарат. ун-та, 2001. $178 \mathrm{c}$.

2. Макаров В.3., Новаковский Б.А., Чумаченко А.Н. Эколого-географическое картографирование городов. М.: Научный мир, 2003. 198 с.

3. Макаров В.3., Чумаченко А.Н. Методология и методика градоэкологических исследований с использованием ГИС-технологий // Tp. XII съезда Русского географического общества. Т. 6. Картография. Геоинформатика. Дистанционные методы исследований. 2009. С. 135-143. 
4. Макаров В.3., Чумаченко А.Н., Демин А.М. и др. Опыт разработки геоинформационной системы для схемы территориального планирования муниципального района // Устойчивое развитие территорий: теория ГИС и практический опыт: Материалы междунар. конф., Саратов (Россия) - Урумчи (Китай) - 2008. Саратов, 2008. Т. 1. C. 228-240.

5. Макаров В.3., Молочко А.В., Фролов В.А., Чумаченко A.Н. Моделирование факторов пожароопасной ситуации на нефтесборных пунктах с использованием геоинформационных технологий // Изв. Сарат. ун-та. Новая сер. 2009. Т. 9. Сер. Науки о Земле, вып. 1. С. 32-39.

6. Макаров В.3., Чумаченко А.Н., Федоров А.В., Данилов B.A. Опыт использования геоинформационных технологий в ОАО «Саратовнефтегаз» // Устойчивое развитие территорий: теория ГИС и практический опыт:
Материалы междунар. конф. Саратов (Россия) - Урумчи (Китай) - 2008. Саратов, 2008. Т. 1. С. 240-246.

7. Макаров В.3., Чумаченко А.Н., Савинов В.А., Данилов В.A. Национальный парк «Хвалынский»: ландшафтная характеристика и географическая информационная система. Саратов: Изд-во Сарат. ун-та, 2006. 140 с.

8. Макаров В.З., Чумаченко А.Н., Федоров А.В. Научноорганизационная и учебно-методическая работа лабораторий урбоэкологии и геоинформатики и тематического картографирования географического факультета Саратовского госуниверситета // Развитие физической географии и ландшафтной экологии в Саратовском университете. К семидесятилетию основания кафедры физической географии и ландшафтной экологии / Под ред. В.З. Макарова. Саратов: Изд-во Сарат. ун-та, 2005. C. $25-38$. 